\title{
Diálogos Literários - Literatura, Comparativismo e Ensino, (org. de Agnaldo Rodrigues da Silva)
}

Rosangela SARTESCHI

Universidade de São Paulo

ais do que uma metodologia de pesquisa, comparar textos produzidos por artistas de países e continentes distintos, ainda que ligados por uma língua e linha de pensamentos comuns, é postura ideológica.

Por um lado, tem-se a consciência de que o processo esmagador de globalização ora em curso na história mundial provoca, no limite, a destruição dos estados nacionais, suas economias bem como expressões políticas e culturais dos países excêntricos que, fragilizados, cada um à sua maneira, não têm encontrado outra alternativa senão a incondicional adesão ao modelo (im)posto.

Por outro lado, a literatura e os estudos literários têm demonstrado que a atual acentuação de denominadores comuns de nações diferentes e, mais ainda, daquelas que se desprenderam de uma matriz comum, como é o caso do Brasil e dos países africanos de língua portuguesa, podem contribuir, por mais paradoxal que possa parecer à primeira vista, para ressaltar particularidades, afirmando e firmando culturas e nações.

Como nos lembra Maria Aparecida Santilli, não se trata de, ao comparar literaturas "nacionais", polarizar individualidade com dependência. Ao contrário, trata-se de ressaltar tais particularidades "na fisionomia que suas respectivas tradições específicas determinaram e que se obliteraram, embora correndo no leito de um veículo de comunicaşão compartilhado." (SANTILLI, 2003)

Comparar diversidades, mundos, pessoas e realidades individuais através dos estudos literários é uma maneira de demonstrar que esse contato ao contrário de ser um mal per se, é um processo antes de tudo enriquecedor. A aproximação e o contato de povos diferentes e a observância das semelhanças e/ou dessemelhanças daí resultantes não implicam em destruição de culturas, mas constituem um instrumento para uma melhor compreensão do outro, do que é diferente. 
Em outras palavras, devemos ser capazes de comparar textos que trazem uma forma de pensar diversa da nossa e sermos capazes de interpretá-la em conjunto, porém cada uma delas composta de uma pauta e um desenvolvimento, com suas formações e lógicas internas, refletindo um sistema de reflexão externo, todas elas interagindo e coexistindo entre si.

Para o estudioso da área, a finalidade é, portanto, romper o isolamento e observar em conjunto e, em contraponto, várias séries e culturas literárias, ultrapassando os nacionalismos limitadores, como bem destacou Maria Aparecida Santilli.

Nessa perspectiva, o livro Diálogos Literários: literatura, comparativismo e ensino, organizado pelo professor da Universidade do Estado de Mato Grosso (Unemat), Agnaldo Rodrigues da Silva, é uma importante contribuição para o debate em torno de questões concernentes aos estudos comparados das literaturas de língua portuguesa.

Diálogos Literários: literatura, comparativismo e ensino reúne vinte e sete ensaios de autoria de pesquisadores experientes e consagrados como Benjamin Abdala Jr., Tania Macêdo, Nelly Novaes Coelho, Jane Tutikian, Inocência Mata e Teolinda Gersão e de jovens e promissores pesquisadores, destacando-se Agnaldo Rodrigues da Silva e Vera Maquêa sobre as literaturas de língua portuguesa (brasileira, portuguesa, moçambicana, cabo-verdiana e angolana) em diálogo com outras áreas do conhecimento - história, antropologia, sociologia, educação, linguística - e também com outras artes - cinema, teatro e música.

Um ponto relevante a destacar é a diversidade e a pluralidade dos aspectos abordados e pontos de vista que emanam não apenas dos centros já consolidados nos estudos comparativistas das literaturas em língua portuguesa como também dão vez e voz a espaços emergentes nessa área de investigação (dezenove artigos da coletânea são assinados por professores e pesquisadores da Universidade do Estado do Mato Grosso).

Assim, por meio dessa gama de reflexões sobre as literaturas produzidas nos países de língua portuguesa, abordam-se questões como a construção identitária, dominação e resistência cultural no mundo globalizado, diálogos literários e culturais entre os países de língua portuguesa, história e ficção: limites e abrangências, perspectivas comparatistas, hibridismos, fronteiras políticas e culturais, utopias e distopias na constituição das culturas mestiças.

Como bem destaca Vera Maquêa, na apresentação do livro, «são estes textos, eles mesmos, trechos da história do nosso tempo, compondo o mosaico de nossa vontade 
de coerência e nos visitando na estrangeirice que experimentamos no mergulho em nossas próprias águas».

Nas viagens propostas, o leitor é convidado a desvelar outras margens, abrindo-se, assim, para outras perspectivas histórico-sociais e culturais que se entrelaçam nas tramas da ficção. Em seu texto de abertura da coletânea - "O Brasil e a América Latina: imagens literárias da travessia do rio" - Benjamin Abdala Jr. traz a imagem da travessia do rio Amazonas empreendida por Ernesto Guevara, retratada no filme Diários de Motocicleta, de Walter Salles, como metáfora desse processo:

O futuro «Che» conseguia ultrapassar, assim, limitações físicas e de origem social, embalado pelo sonho de romper fronteiras de toda ordem. Entrecruzamse sua geografia interior com a exterior da ambiência latino-americana. Nas malhas da bacia da integração subcontinental, convergindo para uma espécie de banda larga de ordem supranacional, confluem pedaços de muitas culturas. No grande rio, símbolo da biodiversidade e das misturas que nos envolvem, é possível descortinar fluxos capazes de integrar dinamicamente o diverso. Uma rede que se desloca da ficção para o referente, como um mito a «fecundar a realidade» (Fernando Pessoa), como ocorre nas formulações do pensamento social de Mariátegui. A rede possui bandas que se alimentam recursivamente, abrindo a possibilidade de muitas margens no processo de combinação, mas estatuindo uma direção para o conjunto contraditório dos fluxos. Como nos diários de Ernesto Guevara e de Alberto Granado, as muitas margens registradas na travessia são janelas abertas para as margens do conhecimento - uma travessia por fronteiras comunitárias de cooperação, de forma equivalente à realização supranacional do filme. Isto é, formas de cooperação capazes de emocionar a todos que ainda cultivam algum cantinho de dignidade. (ABDALA JR., 2008)

Deparamo-nos, então, com textos que abordam autores como os brasileiros João Guimarães Rosa, Milton Hatoum, Mário de Andrade, Manoel de Barros, Clarice Lispector, Monteiro Lobato, Cecília Meireles, Graciliano Ramos, João Ubaldo Ribeiro, os moçambicanos Mia Couto e José Craveirinha, os angolanos Boaventura Cardoso, Viriato da Cruz, José Luandino Vieira, Pepetela, os cabo-verdianos Manuel Lopes e Orlanda Amarílis e os portugue- 
ses Lobo Antunes, Maria Judite de Carvalho, Lídia Jorge e Florbela Espanca sempre pela via dialógica entre suas escrituras.

Devemos, ainda, ressaltar a necessária contribuição de apresentação de autores mato-grossenses menos conhecidos, como Juliano Moreno e Dom Francisco de Aquino Corrêa bem como a apresentação de um panorama sobre o cenário artístico teatral da província de Mato Grosso entre os séculos XVIII e XIX, dando a conhecer ao publico, assim, novas dicções.

Nessa medida, os pesquisadores constantes da presente coletânea deixam antever que a cultura e a literatura teriam, nos países periféricos aqui abordados, papel decisivo na resistência ao poder das forças do centro hegemônico, a fim de manter suas tradições culturais vivas e contribuir para a formação de suas identidades. Jane Tutikian em seu texto "Questões de identidade nas literaturas portuguesa e luso-africanas", em certa medida, aponta para o que pode ser considerado o tom geral da coletânea ao afirmar que:

Diante do multiculturalismo e do novo imperialismo, o fenômeno se repete, a literatura, tomada como uma expressão simbólica, produto da cultura e da história, mas também reinterveniente na história e na cultura - e o conceito é de Pageaux - representa foco de resistência, e as experiências das ex-colônias na África, e a própria experiência portuguesa bem o atestam.

A busca da identidade, nesse fim/início de século, necessariamente, pela recuperação de certos valores autóctones de raízes específicas, seja para resgatar a tradição [...] seja para tentar construir uma nova tradição, no mundo novo, o da reconstrução democrática e o da entrada na União Europeia e no multiculturalismo. (TUTIKIAN, 2008)

Essas construções identitárias, que firmam e afirmam nações e culturas, explicitam o processo de transculturação, conceito difundido por Ángel Rama, como a capacidade que uma determinada sociedade tem de elaborar uma cultura original, mesmo sob circunstâncias adversas a que, por ventura, tenha sido submetida, em que se percebe a existência de uma energia criadora que atua com desenvoltura a partir da herança particular e das incidências provenientes do exterior.

Destaque-se, ainda, que, como nos lembra Edward Said, a leitura e a análise dos considerados grandes textos culturais metropolitanos não existiriam sem 
os movimentos de resistência que ocorreram por todas as partes das periferias contra o império:

E hoje escritores e estudiosos do mundo ex-colonizado têm imposto suas diversas histórias, têm mapeado suas geografias locais nos grandes textos canônicos do centro europeu. E dessas interações sobrepostas, mas divergentes, estão começando a aparecer as novas leituras e conbecimentos. (SAID, 1998)

Assim, os textos que compõem a coletânea iluminam questões substantivas para aqueles que se debruçam sobre as literaturas de língua portuguesa, suas heterogeneidades e singularidades:

"Há muitas formas de travessias [...] Travessias mais tranquilas ou mais problemáticas. São modos de ser e de estar no mundo bastante diferenciados, comutáveis, intercambiáveis, recursivos.” (ABDALA JR, 2008)

\section{Referências Bibliográficas}

RAMA, Ángel. “Os processos de transculturação na narrativa latino-americana” In: AGUIAR, Flávio \& VASCONCELOS, Sandra (org.). Angel Rama - Literatura e cultura na América Latina. São Paulo: Edusp, 2001.

SAID, Edward. Cultura e Imperialismo. São Paulo: Companhia das Letras, 1995.

SANTILLI, Maria Aparecida. "Identidade e justiça: categorias éticas e estéticas. O Próprio e o comum, nas Literaturas de Língua Portuguesa" In: Paralelas e Tangentes entre as Literaturas de Lingua Portuguesa. São Paulo: Arte \& Ciência. Coleção Via Atlântica, 2003.

SILVA, Agnaldo Rodrigues da (Org). Diálogos literários - literatura, comparativismo e ensino. São Paulo: Ateliê Editorial, 2008. 